\title{
A Novel Technology for Generation of Electricity and Cold by Using Energy Potential of Transmission Line's High Pressure Gas
}

\author{
Zohrab Melikyan \\ HVAC Department, National University of Architecture and Construction of Armenia, Yerevan 0009, Armenia
}

Received: July 28, 2015 / Accepted: September 07, 2015 / Published: October 31, 2015.

\begin{abstract}
The main objective of this paper is to develop a novel technology for combined generation of electricity and cold by using energy potential of transmission line's high pressure gas. For this purpose, the reduction of high pressure of the gas in gas distribution station instead of useless expansion throttling process is suggested to realize by adiabatic expansion, which is executed in a gas expanding turbine. Herewith, the gas distribution station is turned into energy and cold generating plant. Simultaneous operation of energy and cold generating plant is described. A method and appropriate formulas for determination of design characteristics of considered plant are suggested. A new method for reveres order of calculation and design of the cold store based on the use of expanded cold gas as cooling agent is developed. Calculations and analysis prove high energy efficiency of suggested technology, the wide use of which will provide significant production of cheap electricity and cold and as well as reduction of fossil fuel consumption.
\end{abstract}

Key words: Natural gas, gas distribution station, throttling valve, turbo-expander, isenthalpic, adiabatic.

\section{Introduction}

At the end of main supply pipelines of gas transporting systems, the gas still possesses rather high pressure reaching up to $2,000 \mathrm{kPa}$. However, such a high pressure of the gas needs to be reduced to $300 \mathrm{kPa}$ before gas distribution by low or medium pressure networks of towns. Usually in gas distribution stations, the gas pressure is reduced mainly by throttling processes in throttling valves. Nevertheless, the throttling of the gas eliminates its energy residual potential, while it could be converted into useful electricity or cold, the use of which will provide rather large public benefit, and as well as keeping the environment free of greenhouse gases emissions. To realize such a goal, an attempt has been done to develop a novel technology serving for

Corresponding author: Zohrab Melikyan, Dr., professor, research fields: gas distribution engineering, refrigeration engineering and air conditioning. E-mail: zohrabmelikyan@yahoo.com. generating energy and cold by using transportaion pipeline's gas.

\section{Analysis of Energy Generating Gas Expansion Thermodynamic Processes}

In gas distribution stations for reducing the pressure of the gas, traditionally isenthalpic thermodynamic process of throttling is being used. The state of natural gas in underground gas transporting pipeline, just before throttling, is characterized by pressure $P_{1}=$ $2,000 \mathrm{kPa}$ and by temperature of the ground, assumed $t_{1}=10{ }^{\circ} \mathrm{C}$. The state of the gas with mentioned parameters is represented by the point " 1 " on enthalpy - pressure $(i-\log P)$ diagram of natural gas (methane) [1] which is given in Fig. 1.

In the diagram the isenthalpic throttling expansion process from initial pressure $P_{1}=2,000 \mathrm{kPa}$ to final low pressure $P_{1^{\prime} \text { tr }}=300 \mathrm{kPa}$ is represented by the line "1-1'tr". In this process, the gas is cooled from $t_{1}=10{ }^{\circ} \mathrm{C}$ to $t_{1}{ }^{\prime}$ tr $=0{ }^{\circ} \mathrm{C}$. The power $N(\mathrm{~kW})$, in 


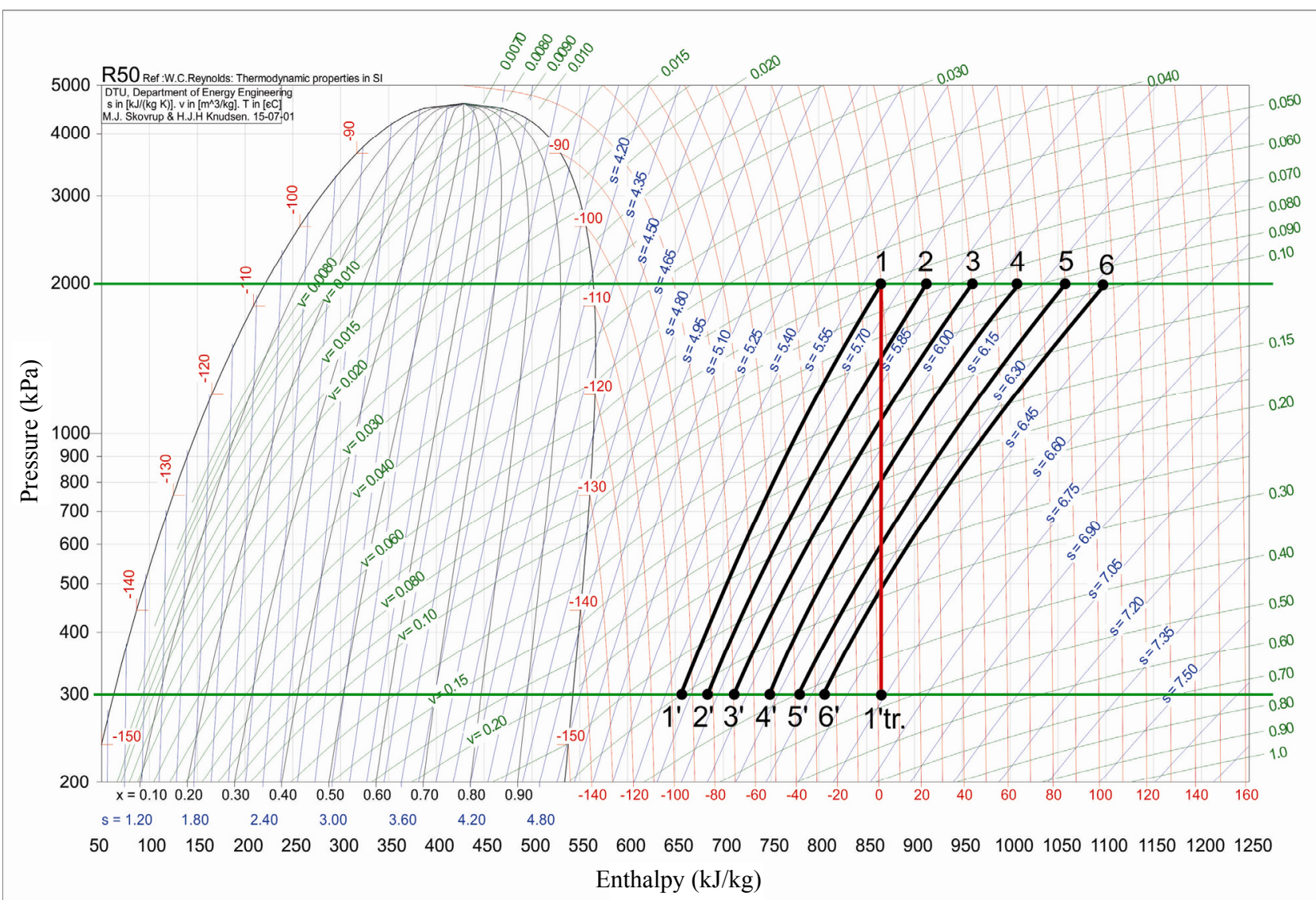

Fig. 1 Isentropic and adiabatic expansion processes of natural gas from $2,000 \mathrm{kPa}$ to $300 \mathrm{kPa}$ on $(i-\log P)$ diagram at different initial temperatures of the gas.

expansion processes is determined by Eq. (1) [2]:

$$
N=G_{g . s p p} \Delta i
$$

where, $G_{g . s p p}$-mass flow rate of gas in gas expanding equipment $(\mathrm{kg} / \mathrm{s}) ; \Delta i$ - difference of initial and final specific enthalpies of gas $(\mathrm{kJ} / \mathrm{kg})$.

As isenthalpic throttling process takes place without change of enthalpy, no work is executed.

\section{Developing of Gas Distribution Modified}

\section{Station for Combined Generation of Electricity and Cooled Gas}

Eq. (1) allows concluding that, gas distribution stations can perform as rather big sources of energy, if they are furnished with gas adiabatic expansion equipment. For this purpose, it is suggested to replace the throttling valve of conventional gas distribution station by turbo-expander. In this case, the high pressure transmission pipeline gas with initial enthalpy $i_{1}=860 \mathrm{~kJ} / \mathrm{kg}$ is expanded adiabatically from $2,000 \mathrm{kPa}$ to $300 \mathrm{kPa}$ and rotates the wheel of turbo-expander. On the driving shaft of turbo-expander, an electric generator is mounted which converts the energy of rotation into electricity. As can be seen from Fig. 1, due to adiabatic expansion, the gas at the outlet of turbo-expander gets temperature $-110{ }^{\circ} \mathrm{C}$ and enthalpy $i_{1},=660 \mathrm{~kJ} / \mathrm{kg}$. Supplying of such a cold gas into distribution network is not allowed [3, 4]. For this reason, before expansion in turbo-expander, it is becoming necessary to heat the gas from $+10{ }^{\circ} \mathrm{C}$ to an appropriate temperature. After expansion, the gas of lower pressure is supplied into gas distribution network or into heat exchanger of the cold store, where is used as cooling agent. The cold store is built in proximity of the gas distribution station, where cold gas is used for cooling the stored food, for instance 
meat. In such cold store, the inside temperature should be kept at $-18{ }^{\circ} \mathrm{C}$ to $-20{ }^{\circ} \mathrm{C}$ [5]. However, the expanded gas at the outlet of turbo-expander gets much lower temperature, than $-18{ }^{\circ} \mathrm{C}$. For avoiding freezing of stored goods, the temperature of gas at the outlet of turbo-expander should be approximately $-25{ }^{\circ} \mathrm{C}$. From Fig. 1, it is clear that for obtaining $-25{ }^{\circ} \mathrm{C}$ final temperature at the outlet of turbo-expander, the initial temperature of the gas at the inlet should be $t_{6}=105{ }^{\circ} \mathrm{C}$ (see processes 6-6', Fig. 1). However, temperature of the high pressure gas in underground transmission main pipeline is $+10{ }^{\circ} \mathrm{C}$. Therefore, for providing $-25^{\circ} \mathrm{C}$, final temperature the main pipeline gas, before entering into turbo-expander, should be preheated from $10{ }^{\circ} \mathrm{C}$ to $105^{\circ} \mathrm{C}$ in a gas heater.

\section{Structure of Gas Distribution Station of Energy and Cooled Gas Generation, Equipped with a Preheater}

The scheme of gas distribution station with combined production of electricity and cooled gas, equipped with gas heater is given in Fig. 2.

Preheating of the gas can be accomplished in a simple apparatus, the sketch of which is given in Fig. 3.

In fact, the suggested gas heater is a sealed furnace with round masonry made of fire resistant brick. In the bottom of fire chamber, which is covered with steel sheet, the gas burner is adjusted. The burner of fuel gas is connected with fuel gas pipe. From gas transporting main pipeline, the gas with temperature $10{ }^{\circ} \mathrm{C}$ passes to the annulus gap between fire chamber and brick vertical cylinder where is heated up to $105{ }^{\circ} \mathrm{C}$. The flue gases are extracted outside through the chimney. Heated gas enters into turbo-expander where is expanded adiabatically and is cooled. The quantity of fuel $B_{f . g a s}\left(\mathrm{~m}^{3} / \mathrm{h}\right)$, consumed for preheating of high pressure gas is determined by the following ratio:

$$
B_{\text {f.gas }}=\frac{Q_{\text {pr.heat }}}{\eta_{\text {gas.heat }} Q_{\text {gas }}}
$$

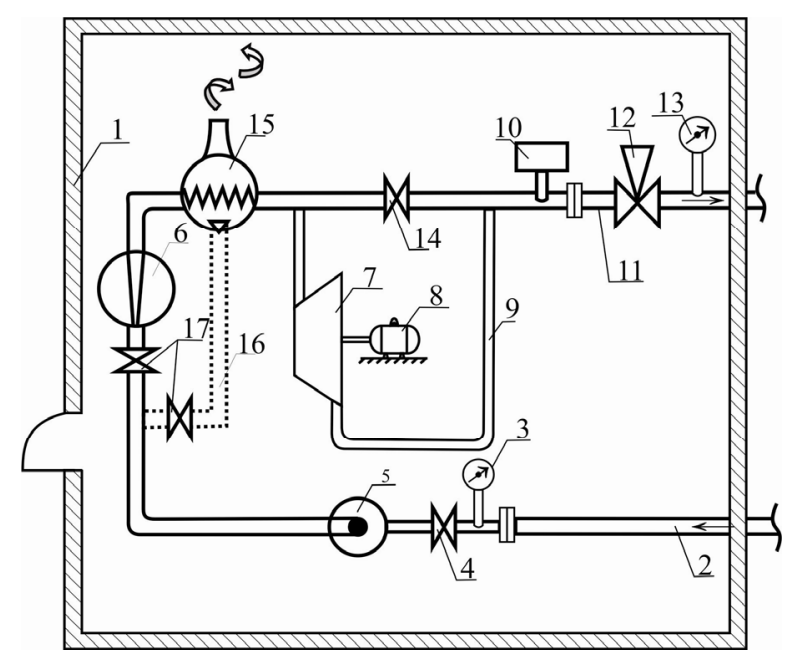

Fig. 2 Scheme of gas distribution station of electricity and cooled gas combined generation.

1-gas distribution station house, 2-gas transportation main pipeline, 3-manometer, 4-gas flow controlling valve, 5-oil strainer, 6-gas flow meter, 7-turbo-expander, 8-electric generator, 9-medium pressure gas pipeline, 10-gas odorizer, 11 -odorized gas supply tube to gas distribution network, 12-gas pressure automatic controller, 13-manometer, 14-by-passing valve, 15-heater of high pressure gas, 16-fuel gas pipe, 17-valves.

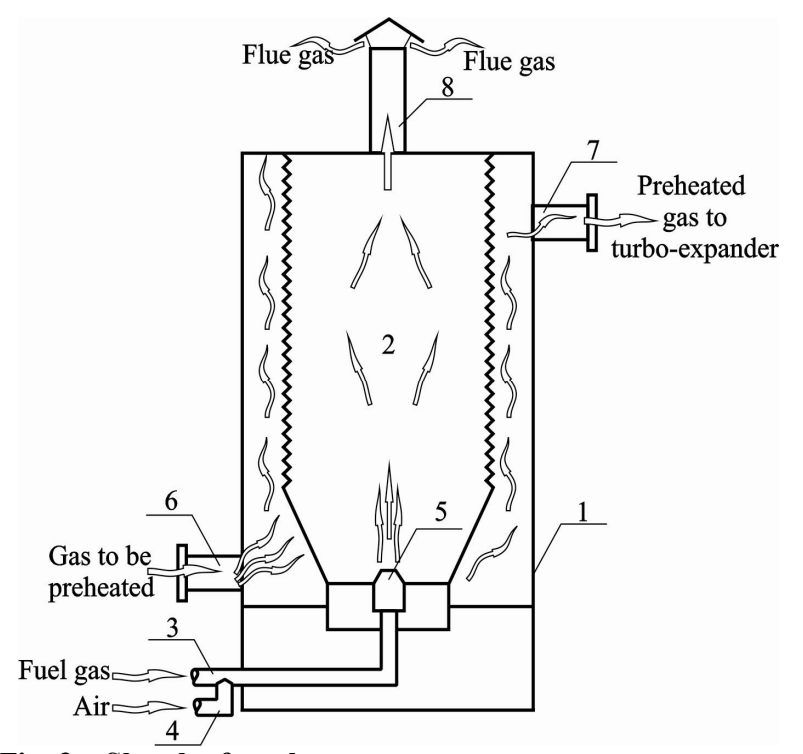

Fig. 3 Sketch of gas heater.

1 -insulated cylinder made of fire-resistant brick, 2-fire chamber with heating steel surface, 3-fuel-gas pipe, 4-air pipe to gas burner, 5-fuel gas burner, 6- high pressure gas to be heated, 7-tube of preheated gas to turbo-expander, 8 - chimney.

where, $Q_{\text {pr.heat }}-$ required heat for gas preheating $(\mathrm{kW})$, $\eta_{\text {gas.heat }}-\mathrm{COP}$ of gas heater, which can be assumed $\eta_{\text {gas.heat }}=0.85, Q_{\text {gas }}-$ gas combustion specific heat, 
assumed $Q_{\text {gas }}=9.3 \mathrm{kWh} / \mathrm{m}^{3}$.

The required heat $Q_{\text {pr.heat }}(\mathrm{kW})$ needed for gas preheating, is determined by Eq. (3):

$$
Q_{\text {pr.heat }}=G_{g . s p p} c_{\text {gas }}\left(t_{g 1}-t_{g}\right)
$$

where, $G_{g . s p p}$ - mass flow rate of gas being preheated $(\mathrm{kg} / \mathrm{s}), c_{\text {gas }}$-specific heat of natural gas which equals to $2.22 \mathrm{~kJ} /\left(\mathrm{kg} \cdot{ }^{\circ} \mathrm{C}\right)[6], t_{g 1}=105{ }^{\circ} \mathrm{C}$-temperature of preheated gas at the inlet of turbo-expander $\left({ }^{\circ} \mathrm{C}\right), t_{g}=$ $10{ }^{\circ} \mathrm{C}$ - temperature of the gas at the end of main gas transporting pipeline $\left({ }^{\circ} \mathrm{C}\right)$.

Solving together Eqs. (3) and (2) and making some simplifications, the following formula for determining the quantity of fuel gas $B_{f . g a s}\left(\mathrm{~m}^{3} / \mathrm{h}\right)$ is obtained:

$$
B_{f . \text { gas }}=\frac{G_{g . s p p} c_{\text {gas }}\left(t_{g 1}-t_{g}\right)}{\eta_{\text {gas.heat }} Q_{\text {gas }}}
$$

The value of $G_{g . s p p}(\mathrm{~kg} / \mathrm{s})$, can be determined by the formula as follows:

$$
G_{g . s p p}=\frac{v_{g . s p p} \cdot n_{p e r s} \cdot \rho_{\text {gas }} \cdot \omega}{8,760 \times 3,600}
$$

where, $v_{g . s p p}$-annual gas consumption by one resident of urban district $\left(\mathrm{m}^{3} /\right.$ person per year $)$ [3], $n_{\text {pers }}$ - number of gas consumers in urban district, $\rho_{\text {gas }}$ $=0.7 \mathrm{~kg} / \mathrm{m}^{3}$ - density of natural gas.

The capacity factor is determined by dividing the actual output with the maximum possible output. The capacity factor for gas supply distribution system, operating with base load regime is assumed $\omega=0.9$ [4].

Taking into account that, annual gas consumption by 1 resident makes $v_{g . s p p}=470 \mathrm{~m}^{3} /$ (person per year) [4], for a medium city with $n_{\text {pers }}=1,000,000$ residents, the mass flow rate of gas $G_{\text {g.spp }}(\mathrm{kg} / \mathrm{s})$, which passes through the turbo-expander and is totally supplied to the urban districts distribution network, calculated by Eq. (5) makes:

$$
G_{g . s p p}=\frac{470 \times 1,000,000 \times 0.7 \times 0.9}{8,760 \times 3,600}=9.4 \mathrm{~kg} / \mathrm{s}, \text { or }
$$

$9.4 \mathrm{~kg} / \mathrm{s} /\left(0.7 \mathrm{~m}^{3} / \mathrm{kg}\right)=13.4 \mathrm{~m}^{3} / \mathrm{s}$, or $48,288 \mathrm{~m}^{3} / \mathrm{h}$ or $423,000,000 \mathrm{~m}^{3} /$ year.

Assuming as well that, specific heat of gas $c_{\text {gas }}=$ $2.22 \mathrm{~kJ} /\left(\mathrm{kg} \cdot{ }^{\circ} \mathrm{C}\right)[6], t_{g 1}=105{ }^{\circ} \mathrm{C}, t_{g}=10{ }^{\circ} \mathrm{C}, \eta_{\text {gas. heat }}=$ 0.85 and $Q_{\text {gas }}=9.3 \mathrm{kWh} / \mathrm{m}^{3}$, by the help of Eq. (4), the following quantity of fuel gas consumption $B_{f . g a s}$ $\left(\mathrm{m}^{3} / \mathrm{h}\right)$ is obtained:

$$
B_{\text {f.gas }}=\frac{9.4 \times 2.22 \times(105-10)}{0.85 \times 9.3}=251 \mathrm{~m}^{3} / \mathrm{h}
$$

So, the quantity of fuel gas $B_{f . \text { gas }}=251 \mathrm{~m}^{3} / \mathrm{h}$, consumed for preheating of the gas with quantity $G_{\text {g.spp }}=48,288 \mathrm{~m}^{3} / \mathrm{h}$, supplied to the district's gas distribution network or to the cold store, makes only $0.52 \%$ of the whole gas, supplied to the network.

\section{Quantity of Electric Energy Generated by the Set of Turbo-Expander and Electric Generator}

The specific quantity of energy $L(\mathrm{~J} / \mathrm{kg})$, produced in turbo-expander in consequence of adiabatic process of gas expansion is determined by Eq. (6) [8]:

$$
L=\frac{Z R T_{1}}{k-1}\left[1-\left(\frac{P_{2}}{P_{1}}\right)^{\frac{k-1}{k}}\right]
$$

where, $Z=1.04$ compressibility factor of natural gas [8], $R$ - gas constant of natural gas (methane) equal to $518.3 \mathrm{~J} /\left(\mathrm{kg} \cdot{ }^{\circ} \mathrm{C}\right)[9], T_{1}=(105+273)=378 \mathrm{~K}$-initial temperature of preheated gas at the inlet of turbo-expander, $k=1.31$-adiabatic or isentropic exponent for methane equal to 1.31 [9], $P_{1}$ and $P_{2}$ - pressures of the gas at the inlet and outlet of turbo-expander $(\mathrm{kPa})$.

As can be seen from Eq. (6), the quantity of energy produced by turbo-expander depends mainly on expansion rate $P_{2} / P_{1}$. In developed gas distribution station, the expansion ratio of natural gas in turbo-expander makes: $P_{2} / P_{1}=300 / 2,000=0.15$. According to Eq. (6) and above given thermo-physical data of natural gas, the produced specific energy $L$ 
makes:

$$
\begin{aligned}
& L=\frac{1.04 \times 518.3 \times(105+273)}{1.31-1}\left[1-(0.15)^{\frac{1.31-1}{1.31}}\right]= \\
& =657,271(1-0.637)=238,000 \mathrm{~J} / \mathrm{kg} \text { or } 238 \mathrm{~kJ} / \mathrm{kg}
\end{aligned}
$$

Taking into account that, the whole $G_{g . s p p}=9.56 \mathrm{~kg} / \mathrm{s}$ gas is expanded in turbo-expander, the absolute value of electric power will make $N=9.56 \times 238=2,275.3 \mathrm{~kW}$.

Summarizing the results of above investigation, it is becoming clear that, the modified gas distribution station turns to an electric power plant with $N=$ $2,275.3 \mathrm{~kW}$, or 2.275 MW electric power. The annual production of electricity of this power plant makes 2,275.3 $\mathrm{kW} \times 8,760 \mathrm{~h}=19,931,628 \mathrm{kWh}$, which can be sold to the city electricity network utility company for $19,931,628 \mathrm{kWh} \times 0.09 \$ / \mathrm{kWh}=1,793,847 \$ /$ year (0.09 $\$ / \mathrm{kWh}$ - tariff of electricity for instance in Armenia). Should be taken into account that, if turbo-expander is charged in $50 \%$ of its power, its energy efficiency decreases in 18\%-20\%.

\section{Structure and Operation of Cold Store Functioning with Gas Cooling Agent}

Besides electricity generation, the modified gas distribution station can operate as well as a cold store. To realize of this purpose the cooled gas at temperature $t_{c . g .1}=-25{ }^{\circ} \mathrm{C}$ is supplied from turbo-expander into air to gas heat exchanger installed inside the cold store [10]. Here, it takes heat from cold store air, which circulates through heat exchanger and is wormed from $t_{c . g .1}=-25{ }^{\circ} \mathrm{C}$ to temperature $t_{c . g .2}=$ $-23{ }^{\circ} \mathrm{C}$. At the same time, the cold store air at temperature $t_{c . s t .1}=-18{ }^{\circ} \mathrm{C}$ enters into heat exchanger and is cooled to $t_{c . s t .2}=-19^{\circ} \mathrm{C}$. The partially warmed gas moving from heat exchanger to low pressure distribution network at temperature $t_{c . g .2}=-23{ }^{\circ} \mathrm{C}$ still is too cold to be supplied into district distribution network. For avoiding damages of gas network, a necessity of secondary heating of the low pressure gas, before supplying to urban gas distribution low pressure network arises. The simplified scheme of modified gas distribution station, equipped with gas turbo-expander, electric generator, primary and secondary gas heaters and cold store is represented in Fig. 4.

The suggested cold store operates in the following way: the gas with temperature $t_{g}=10{ }^{\circ} \mathrm{C}$ from high pressure gas transmission main pipeline (1) enters into primary gas heater (2) where is heated to $t_{g .1}=105^{\circ} \mathrm{C}$ and by suction line is inhaled into turbo-expander (3) where is expanded adiabatically and is cooled to $t_{c . g .1}$ $=-25^{\circ} \mathrm{C}$. By pipe (5), the cooled gas enters into heat exchanger (7), installed in the cold store (6) [5]. As a result of heat absorption from stored food (8), and all other heat gains the gas is warmed to $t_{c . g .2}=-23{ }^{\circ} \mathrm{C}$ and by pipe (9) is directed to secondary gas heater (10). In this heater, gas is secondary heated to admissible temperature $t_{g}=+5{ }^{\circ} \mathrm{C}$ which allows to escape damaging of gas distribution network. Passing the pressure controller (11) the low pressure gas is supplied to the main pipeline (12) of low pressure gas supply urban network.

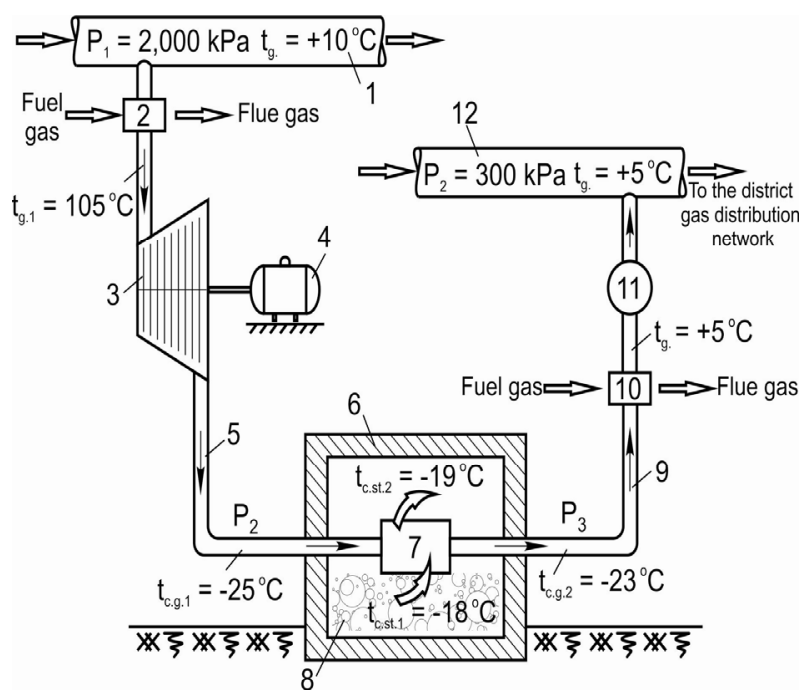

Fig. 4 Simplified scheme of modified gas distribution station equipped with gas turbo-expander, electric generator and cold store.

1-high pressure gas transmission main pipeline, 2-primary gas heater, 3-gas turbo-expander, 4-electric generator, 5-pipe of cooled gas, 6-thermoinsulated cold store, 7-air to gas heat exchanger, 8- stored food, 9-partially warmed gas pipeline, 10-gas secondary heater, 11-pressure controller, 12 -main pipeline of low pressure gas distribution network. 


\section{A Novel Technology for Generation of Electricity and Cold by Using Energy Potential of Transmission Line's High Pressure Gas}

\section{Reversal Method for Calculation and Design of Suggested Cold Store}

In contrast to ordinary cold stores, the calculation and design of the suggested one is executed in opposite way. That is to say, for ordinary cold stores, the tonnage: construction, sizes, kinds and quantity of stored food and other characteristics of the cold store are given. Based on listed data, the values of heat gains, cooling demand and all characteristics of refrigeration equipment are determined. For considered cold store, only the cooling capacity in form of quantity of cooled gas and its temperature are available. In such conditions tonnage, construction sizes of the cold store and other characteristics have to be determined. The cooling capacity of suggested cold store $Q_{\text {c.st. }}(\mathrm{kW})$ can be determined by the following balance of heat flows:

$$
Q_{c . s t .}=Q_{a v .}-Q_{h . g .}-Q_{i n t .}-Q_{v e n t .}
$$

where, $Q_{a v}$. - available cooling capacity of natural gas, cooled in turbo-expander $(\mathrm{kW}), Q_{h . g}$ - heat gains through external constructions of cold store $(\mathrm{kW})$, $Q_{\text {int. }}$-internal heat rejections from personnel, and electric and lighting equipment $(\mathrm{kW}), Q_{\text {vent. }}$ - heat, transferred from ventilation air to cold store's internal air $(\mathrm{kW})$.

The value of available cooling capacity of natural gas, cooled in turbo-expander, $Q_{a v} .(\mathrm{kW})$, is determined by the expression as follows:

$$
Q_{a v .}=G_{g . s p p} \cdot c_{g a s} \cdot T_{c . g}
$$

where, $T_{c . g}=-25+273=248 \mathrm{~K}$-absolute temperature of cold gas at the outlet of turbo-expander.

Therefore:

$$
Q_{a v .}=9.4 \mathrm{~kg} / \mathrm{s} \times 2.22 \mathrm{~kJ} /(\mathrm{kg} \cdot \mathrm{K}) \times 248 \mathrm{~K}=5,175 \mathrm{~kW}
$$

which should compensate all mentioned heat flows, that is to say:

$$
Q_{a v .}=Q_{c . s t .}+Q_{h . g .}+Q_{\text {int. }}+Q_{\text {vent. }}
$$

The suggested reversal method recommends designing the cold store based on assumptions of values of heat flows as parts of available cooling capacity $Q_{a v}$. of natural gas. The further designing of constructions, sizes and equipment should be realized in a way to provide quoted heat flows. According to the following quotas, the heat flows are the followings:

(1) heat gains through external constructions of cold store $Q_{h . g}=0.35 Q_{a v}=0.35 \times 5,175 \mathrm{~kW}=1,811 \mathrm{~kW}$;

(2) internal heat rejections from personnel and equipment $Q_{\text {int. }}=0.2 Q_{a v}=0.2 \times 5,175 \mathrm{~kW}=1,035 \mathrm{~kW}$;

(3) heat, transferred from ventilation air to cold store's air, $Q_{\text {vent. }}=0.2 Q_{a v}=0.2 \times 5,263 \mathrm{~kW}=1,035 \mathrm{~kW}$.

Total heat gains make:

$$
Q_{\text {tot.h.fl. }}=1,811+1,035+1,035=3,881 \mathrm{~W}
$$

Quantity of heat $Q_{c . s t .}(\mathrm{kW})$ rejected from stored food will be the rest of available cooling capacity of the natural gas, i.e.,

$$
Q_{c . s t .}=Q_{a v .}-Q_{t o t . h . f l}=5,175-3,881=1,294 \mathrm{~kW}
$$

So, quantity of heat $Q_{c . s t}(\mathrm{~kW})$, rejected from stored food, which actually is the cooling capacity of cold store is calculated by Eq. (10):

$$
Q_{c . s t .}=G_{f . s p p}\left(i_{f .1}-i_{f .2}\right)
$$

where, $G_{f . s p p}$-quantity of chilled fresh food supplied into cold store $(\mathrm{kg} / \mathrm{s}), i_{f .1}=72 \mathrm{~kJ} / \mathrm{kg}$ [11]—initial enthalpy of preliminary chilled fresh meat supplied with temperature $t_{f .1}=-10{ }^{\circ} \mathrm{C}, i_{f .2}=47 \mathrm{~kJ} / \mathrm{kg}$ [11] -final enthalpy of stored meat at cold store's temperature $t_{f .2}=-18^{\circ} \mathrm{C}$.

From Eq. (10), follows the equation, allowing to determining quantity of chilled fresh food (meat) supplied into cold store, $G_{f s p p}(\mathrm{~kg} / \mathrm{s})$ :

$$
G_{f . s p p}=\frac{Q_{c . s t .}}{i_{f .1}-i_{f .2}}
$$

Substitute above data for quantities in Eq. (11) and making calculations will obtain the following value of $G_{f . s p p}(\mathrm{~kg} / \mathrm{s})$ :

$$
G_{f s p p}=\frac{1,294 \mathrm{~kW}}{(72-47) \mathrm{kJ} / \mathrm{kg}}=\frac{1,294 \mathrm{~kW}}{25 \mathrm{~kJ} / \mathrm{kg}}=51.8 \mathrm{~kg} / \mathrm{s}
$$

or $186,480 \mathrm{~kg} / \mathrm{h}$; or $4,475,520 \mathrm{~kg} /$ day; or $4,475.5$ ton/day.

The tonnage $M(\mathrm{~kg})$ of cold store is determined by 
the following Eq. (12) [12]:

$$
M=\frac{G_{f . s p p} \times 305}{B \cdot m}
$$

where, 305-number of days of the year during of which the fresh food is supplied into cold store, $B$-rate of food's yearly turnover in cold store, assumed $B=5-6,1$ year [12], $m$-rate of irregularity of daily supply of food, assumed $m=1.5-2.5$.

By the help of quantity of daily supplied food into cold store $G_{f . s p p}=4,475.5$ ton, by Eq. (12), the tonnage $M$, ton of the cold store is calculated:

$$
M=\frac{4,475.5 \text { ton } / \text { day } \times 305 \text { day }}{6 \times 2.5}=91,000 \text { ton }
$$

\section{Method for Determining of Cold Store's Constructive Characteristics}

The value of heat gains $Q_{h . g .}(\mathrm{kW})$ through all external constructions of the cold store was quoted above $Q_{h . g .}=0.35 Q_{a v .}=0.35 \times 5,175 \mathrm{~kW}=1,811 \mathrm{~kW}$, therefore, the external constructions of the cold store ought to be designed in such a way for not to exceed the quoted value $Q_{h . g}=1,811 \mathrm{~kW}$.

For designing of cold store's building construction, materials and their thermo-physical properties should be chosen. For providing required limit of heat gains, the average heat transfer coefficient $k_{\text {const }}\left(\mathrm{W} /\left(\mathrm{m}^{2} \cdot{ }^{\circ} \mathrm{C}\right)\right)$ of walls and ceiling of cold store should be calculated by using Eq. (13):

$$
k_{\text {const. }}=\frac{0.3 Q_{\text {c.st }}}{\left[\left(F_{\text {s.w }}+F_{\text {ceil. }}\right)\left(t_{R}-t_{c . s t}\right)+\Sigma F_{\text {oth.w }}\left(t_{\text {out }}-t_{c . s t}\right)\right]}
$$

where, $F_{\text {s.w }}$ - surface of south facing wall of cold store $\left(\mathrm{m}^{2}\right), F_{\text {ceil. }}$-surface of ceiling of cold store $\left(\mathrm{m}^{2}\right)$, $\Sigma F_{\text {oth.w }}$ - total surface of all other orientations facing walls $\left(\mathrm{m}^{2}\right), t_{R}$ - solar radiation conditional temperature of the boundary air layer on external surfaces of south facing wall and ceiling $\left({ }^{\circ} \mathrm{C}\right), t_{\text {ou }}-$ design temperature of outside air $\left({ }^{\circ} \mathrm{C}\right), t_{c . s t}$-inside temperature of cold store $\left({ }^{\circ} \mathrm{C}\right)$.

The value of solar radiation conditional temperature $t_{R}$ is determined by Eq. (14) $[13,14]$ :

$$
\mathrm{t}_{\mathrm{R}}=t_{\text {out }}+\frac{I \cdot p}{\alpha_{\text {out }}}
$$

where, $I$-solar radiation intensity descending on surfaces of south facing wall and ceiling $\left(\mathrm{W} / \mathrm{m}^{2}\right)$.

It is preferable to design single floor cold store. The constructive characteristics of the cold store can be determined based on its tonnage $M$. Thus, loaded volume $V_{l d}\left(\mathrm{~m}^{3}\right)$ of cold store can be determined by the following ratio:

$$
V_{l d}=M / m_{l d}
$$

where, $m_{l d}=0.35 \mathrm{ton} / \mathrm{m}^{3}$-norm of loading in $1 \mathrm{~m}^{3}$ of cold store volume [12].

The loaded surface $S_{l d}\left(\mathrm{~m}^{2}\right)$ of cold store is determined by the following ratio:

$$
S_{l d}=V_{l d} / h_{l d}
$$

where, $h_{l d}$-loaded height of single-storey cold storage which, according to Ref. [12], should be taken $4 \mathrm{~m}$.

The cold store's real height $h_{\text {const. }}(\mathrm{m})$ is determined by the following sum:

$$
h_{\text {const. }}=h_{l d}+(0.3-0.5)
$$

Real surface $S_{\text {const. }}\left(\mathrm{m}^{2}\right)$ of cold store is to be determined by the following ratio:

$$
S_{\text {const. }}=S_{l d} / \beta_{S}
$$

where, $\beta_{S}=0.8$ - coefficient for increasing the surface for arranging of aisles in cold store.

The constructional sizes: length $a(\mathrm{~m})$ and width $b$ (m) are determined, assuming square view in plan of the cold store (for reducing heat gains) in the following way:

$$
a=b=\sqrt{S_{\text {cold.st }} .}
$$

\section{Conclusions}

Replacement of throttling valve of conventional gas distribution station by adiabatic turbo-expander makes possible to generate large quantities of electric energy without consumption of fossil fuel.

As a result of adiabatic expansion, the gas is cooled up to $-110^{\circ} \mathrm{C}$, which is not allowed to supplying into 


\section{A Novel Technology for Generation of Electricity and Cold by Using Energy Potential of Transmission Line's High Pressure Gas}

gas distribution network. In order to escape this flaw, the gas of transportation main pipeline before expansion in turbo-expander should be primary preheated up to $105{ }^{\circ} \mathrm{C}$, which, after expansion in turbo-expander, is cooled up to $-25^{\circ} \mathrm{C}$.

A cold store in the proximity of gas distribution station has to be constructed for using the cooled gas as a cooling agent. For avoiding freezing of stored goods, the temperature of gas at the outlet of turbo-expander should not be lower than $-25^{\circ} \mathrm{C}$.

Supply of used cold gas from cold store's heat exchanger into the urban gas distribution network, requires secondary heating of gas from $-23{ }^{\circ} \mathrm{C}$ to $+5{ }^{\circ} \mathrm{C}$ which helps preserving the gas network from damages.

The modification of widely applied gas distribution stations to electric power plant and cold store, allows producing large quantities of electricity and to set up an extremely large cold.

Because of very little quantity of fuel-gas consumed by gas heaters the annual operational cost of suggested technology is little too.

The suggested method for reversal design of the cold store can be applied in other heating and cooling technologies.

\section{References}

[1] Owen, S. M. 2013. "Thermophysical Properties of Refrigerants (Methane R-50).” In ASHRAE Handbook Fundamentals. Vol. 30. Atlanta, GA: ASHRAE, 45-7.

[2] Owen, S. M. 2013. "Thermodynamics and Refrigeration
Cycles." In ASHRAE Handbook Fundamentals. Vol. 2. Atlanta, GA: ASHRAE, 22.

[3] Mokhatab, S., Poe, W. A., and Speight, J. G. 2006. Natural Gas Transmission and Processing. USA: ELSEVIER, 672.

[4] Kolpakowa, N. W. 2014. Gas Distribution. Ekaterinburg: Ural Universiteta, 200.

[5] Owen, S. M. 2006. "Forced Circulation Air Cooler." In ASHRAE Handbook Refrigeration. Vol. 42. Atlanta, GA: ASHRAE, 6.

[6] Poling, B. E., Prausnitz, J. M., and O’Connel, J. P. 2001. The Properties of Gases and Liquids. New-York, Chicago: The McGraw-Hill, 803.

[7] Jila, W. A., Ushakov, M. A., and Brukhanov, O. N. 2003. Gas Supply Networks and Installations. Moscow: Academia, 225.

[8] Tarik, A. S. 2010. Engineering Thermodynamics. UK: Ventus Publishing ApS, 107.

[9] Pavlov, K. F., Romankov, P. G., and Noskov A. A. 2007. Examples and Problems on Course of Processes and Apparatus of Chemical Technology. Saint Petersburg: Chemist, 624.

[10] Fraser, T. W., Skaja, R. A., and Wagner, J. N. 2008. Mass and Heat Transfer. New York: Cambridge University Press, 405.

[11] Owen, S. M. 2006. "Thermal Properties of Food." In ASHRAE Handbook Refrigeration. Vol. 9. Atlanta, GA: ASHRAE, 10.

[12] Kurilev, E. S., and Gerassimov, N. A. 1971. Cold Stores. Leningrad: Machinostroenie, 256.

[13] Melikyan, Z. 2014. "Heating and Cooling Hybrid System and Method for Its Calculation and Design." International Journal of Energy and Power Engineering 3 (6): 296-307.

[14] Melikyan, Z. 2015. "Energy Efficiency and Cost Effectiveness of Solar Water Heaters." International Journal of Energy and Power Engineering 4 (3): 184-8. 